\title{
sciendo
}

\section{ASSOCIATION BETWEEN NATRIURETIC PEPTIDE RECEPTOR 2 (NPR2) RS208158047 POLYMORPHISM AND FATTENING PERFORMANCE OF YOUNG BULLS}

\author{
Jale Metin Kıyıc1 ${ }^{1}$, Zeki Emre Şenöz', Mehmet Ulaş Çınar ${ }^{1,2 \bullet}$
}

\author{
${ }^{1}$ Department of Animal Science, Faculty of Agriculture, Erciyes University, 38039 Kayseri, Turkey \\ ${ }^{2}$ Department of Veterinary Microbiology and Pathology, College of Veterinary Medicine, Washington \\ State University, Pullman, WA 99164, USA \\ •Corresponding author: mucinar@erciyes.edu.tr
}

\begin{abstract}
The objective of this study was to determine fattening performance data for Charolais, Limousin and Blonde d'Aquitaine beef cattle and associate these data with NPR2 gene 8:g.59961937 T>C (rs208158047) mutation. Experiments were conducted with 176 beef cattle (77 Charolais, 66 Limousin and 33 Blonde d'Aquitaine) at nine months of age. Experiments lasted for 9 months and animals were slaughtered at the age of 18 months. Cattle body weights were determined at four different periods: beginning of fattening (d0), 60th day of fattening (d60), 120th day of fattening (d120) and at the end of fattening (sw). In terms of $r s 208158047$ mutation of Charolais, Limousin and Blonde d'Aquitaine breeds, TT and CT genotypes were identified, and CC genotype was not encountered. The association of average daily gain (ADG) in d0-d60, d0-d120 and d0-sw periods with the genotypes of $r \mathbf{2 0 8 1 5 8 0 4 7}$ mutation was found to be significant $(\mathrm{P}<\mathbf{0 . 0 5})$. Greater ADGs were observed in $r$ s208158047-CT genotypes compared to $r$ s208158047-TT genotypes. These results indicate that the selection of bovine $N P R 2$ gene could be used to ensure the breeding direction for growth related traits of the beef cattle.
\end{abstract}

Key words: bovine, SNP, live weight gain, rs208158047, selection signature

Beef is the third most widely consumed meat in the world, provides for about $25 \%$ of meat production worldwide, after pork and poultry at $38 \%$ and $30 \%$, respectively. Globally, cattle meat production has almost tripled since 1961 - increasing from 28 million tons per year to 71 million tons in 2018 (FAO, 2019). Through the transition of human society from nomadic hunter-gatherers to sedentary farming communities in old world continents the earliest domestication of cattle occurred more than 10,000 years ago (Raza et al., 2020 a; Pitt et al., 2019). Selective breeding and genetic improvement during domestication have led to several genomic changes over generations in various animal species including livestock and left genomic foot- 
prints, called selection signatures (Raza et al., 2019; Kijas et al., 2012; Andersson et al., 2012). The elucidation of such signatures could help identification of genes that are difficult to identify through laboratory experiments and may also be useful in corroborating quantitative trait loci (QTL) mapping experiments in livestock (de Simoni Gouveia et al., 2014; Raza et al., 2020 b). Plenty of selection signatures have been identified and continuing to be identified in different livestock species and breeds (de Simoni Gouveia et al., 2014). Nevertheless, Almeida et al. (2019) mentioned about the importance of knowing the genes, annotated selection signature loci and how they biologically act contributed to the current phenotype of the evaluated animals. In two of selection signature studies, Randhawa et al. (2016) found genome-wide average gene density against the number of genes including NPR2 in each prominent region by using the spans of prominent peaks and $\mathrm{Xu}$ et al. (2015) stated a cattle selection signature that may be under positive selection for skeletal morphology and body size, and was annotated to natriuretic peptide receptor B (NPR2) gene on BTA8 around $60 \mathrm{Mbp}$.

The natriuretic peptides (NP) are a family of three polypeptide hormones termed atrial natriuretic peptide (ANP), brain natriuretic peptide (BNP), and C-type natriuretic peptide (CNP) (Anand-Srivastava, 2005). The signal pathway of the C-type natriuretic peptide is a small, secreted peptide (Wang et al., 2015) which binds to a homodimeric transmembrane receptor named natriuretic peptide receptor-B (NPRB) which is encoded by natriuretic peptide receptor 2 (NPR2) gene (Wei et al., 2015). $N P R 2$ functions as a guanylyl cyclase to generate cyclic guanosine monophosphate (cGMP) in chondrocytes, female reproductive organs, and endothelial cells (Potter et al., 2006). NPR-B is encountered in several different tissues including brain, adrenal gland, and uterus (Tamura and Garbers, 2003). The primary task of this protein was also reported to be related to skeletal growth (Bartels et al., 2004). NPR2 gene encodes NPRB, one of two integral membrane receptors for natriuretic peptides. $N P R B$, one of three natriuretic peptides, acts as transmembrane guanyl cyclase and catalyses cGMP synthesis when activated (Potter et al., 2006). NPR2 is directed by a protein group binding intracellular physiological effects to three different cGMP through binding to these receptors. Several experimental models defined the role of the natriuretic peptide signalling system in the regulation of growth (Vasques et al., 2014). A loss-of-function mutation and SNPs in NPR2 gene were shown to be responsible for dwarfism or short stature in human and mouse (Wang et al., 2015; Vasques et al., 2014; Tsuji and Kunieda, 2005).

Therefore, in this experiment, we aimed to determine body weight and body weight gains together with carcass traits and to investigate the association of those traits with bovine NPR2 gene in a multibreed cattle population.

\section{Material and methods}

\section{Ethics statement}

Live weights and post-mortem carcass measurements used were obtained from animals, previously transported, and handled following the guidelines defined by the 
slaughterhouse and the regulations of the Animal Experiments Local Ethics Committee for use of animals in research at Erciyes University.

\section{Animals and phenotypes}

In the study, data obtained from beef cattle raised in an intensive commercial fattening farm operation located in West Anatolia region of Turkey (39 40' 66.79" N, $\left.26^{\circ} 28^{\prime} 84.66^{\prime \prime} \mathrm{E}\right)$ were used. Young bulls were imported from three different farms (a farm per breed) in France and each breed was from different farms in France and animals were genetically not related. Young bulls were neither pregnant nor lactating and placed accordingly to avoid stressful conditions. A total of 176 clinically healthy animals ( $n=77$ Charolais, $n=66$ Limousin, and $n=33$ Blonde d'Aquitaine) with an average age of $272 \pm 25$ days were placed in a free-stall barn and allocated to pens (13-15 animals per pen) in homogenous groups based on breed and live weight. The pens consisted of a straw-bedded area $(12 \times 7 \mathrm{~m})$ and a standing alley $(8 \times 3 \mathrm{~m})$ with feed bunks. All pens were identical, located in the same barn and equipped with one water trough, one concentrate feed station and five roughage intake control feed bunks. Each feed bunk was $0.8 \mathrm{~m}$ wide, $0.75 \mathrm{~m}$ high and $0.74 \mathrm{~m}$ deep. The animals had permanent access to water and salt licks.

Roughage (maize silage, alfalfa, and wheat hay) and concentrate feed (fattening starter feed and fattening feed) were used for animal feeding. Total mixed ration (TMR) was prepared so as to meet daily life and yield allowance of the cattle and supplied to animals in two meals (9:00 am, 4:00 pm). Specific requirements were based on the INRA guidelines for medium-early maturing young bulls with daily gains of around $1000 \mathrm{~g}$. TMR mixtures supplied to animals and nutritional compositions are provided in Supplementary Table 1.

Cattle body weight was determined at the beginning of fattening $(\mathrm{d} 0)$, on the 60 th day (d60), and on the 120th day (d120). At the end of the finishing period, the animals were slaughtered at a commercial slaughter facility according to standard practices. This facility does not use electrical stimulation, which can increase muscle tenderness. Mean slaughter age was $548.70 \pm 5.3$ days. After $1-2 \mathrm{~h}$ of transportation and with no access to feed (water was available) for approximately $24 \mathrm{~h}$ after arrival, final weights were recorded as slaughter weight (sw) immediately before slaughter. Average daily weight gain (adwg) for each animal was calculated for the interval between the weight measurements. The carcass traits that were used as phenotypic traits for association analysis data included: slaughter weight (sw), hot carcass weight (hcw) is the weight of carcass after harvest and removal of the head, the fore-shank below the knee joint, the hind-shank below the hock joint, gastrointestinal tracts and internal organs, cold carcass weight (ccw) is the weight of carcass after 24 h-chill period, dressing percentage (dp) is calculated by dividing the warm carcass weight by the slaughter live weight of the animal and expressing the result as a percentage. Details of phenotypes according to breed are given in the Supplementary Table 2.

\section{SNP selection and genotyping}

Two SNP selection methods were followed in the present study. First, we selected two non-synonymous and one splice region variant mutations in the bovine NPR2 
gene (rs448459527-p.Glu690Gly, rs436074311-p.Leu237Arg and rs456539469c.1352-5T $>$ C). Mutations were selected according to their SIFT (Sorting Intolerant From Tolerant) values which is a program that predicts whether an amino acid substitution affects protein function so that one can prioritize substitutions for further study (Ng and Henikoff, 2003). Secondly, rs208158047, BTA8:g.59961937T>C intronic mutation was selected for genotyping and association analysis according to in silico bovine genome analysis which is available in the Ensembl Genome Browser.

Genomic DNA was isolated from blood samples using a DNeasy Blood \& Tissue Kit (Qiagen, Hilden, Germany) per the manufacturer's instructions, and treated with RNase A (Qiagen, Hilden, Germany). DNA concentration was obtained using a BioSpec-nano (Shimadzu, Duisburg, Germany), and all samples had A260/ A280 ratios >1.8. Bovine NPR2 SNP ( $r s 208158047$, BTA8:g.59961937T $>$ C) was genotyped with the use of TaqMan SNP Genotyping Custom Assays (Invitrogen, Carlsbad, CA). Genotyping was performed by allelic-discrimination with primers (Invitrogen, Carlsbad, CA) and hydrolysis probes (Invitrogen, Carlsbad, CA) for $r s 208158047$ (Forward: CAAATTTCTTGGCCCTGACATTCAA, Reverse: GCAGGAGAAGGTAAGGATGGAATC, VIC-TTGCTGCAAATGATGACAG, FAM-TTGCTGCAAATAATGACAG). PCR reaction medium was composed of $5 \mu \mathrm{l}$ TaqMan Genotyping Master Mix, $0.5 \mu \mathrm{l}$ TaqMan probe, $2 \mu \mathrm{l}$ DNA and $2.5 \mu \mathrm{l}$ water. PCR was conducted with the use of C1000 Touch Thermal Cycler (Bio-Rad, CA, USA) with 1 cycle at $95^{\circ} \mathrm{C}$ for 10 minutes and 40 cycles at $95^{\circ} \mathrm{C}$ for 15 seconds, $60^{\circ} \mathrm{C}$ for 1 minute. At the end of PCR reaction, genotypes were imaged in ABI Prism StepOnePlus Real-Time System (Applied Biosystems, Foster City, CA) device.

\section{Statistical analysis}

An online software (http://www.husdyr.kvl.dk/htm/kc/popgen/genetik/applets/ kitest.htm) was used to analyse the Hardy-Weinberg equilibrium (HWE) and allele frequency for each SNP and statistical significance was defined as $\mathrm{P}<0.05$.

Associations between the rs208158047 SNP genotypes and fattening performance at different ages were analysed by analysis of variance using the GLM (General Linear Model) procedure with SAS 9.0 software (SAS Institute, Cary, NC, USA; Raza et al., 2020 c, d). The association model used was as follows:

$$
Y_{i j k}=\mu+G_{i}+B_{j}+\beta I_{k}+\varepsilon_{i j k}
$$

where $Y_{i j}$ was observations of fattening traits, $\mu$ was population mean, $G_{i}$ was effect of the genotype (two levels), $B_{j}$ was effect of the breed (three levels), $\beta I_{k}$ was covariate effect of the initial weight for daily weight gain ( $\mathrm{d} 0$ weight) and carcass traits (slaughter weight), and $\varepsilon_{i j k}$ was residual error. Covariate effect was calculated by grouping the whole $\mathrm{d} 0$ weight data into four parts between minimum and maximum values; thus, four levels were included into relevant model. 


\section{Results}

Table 1 lists the genotype distribution, genotype frequencies and allele frequencies (Ne, He and Ho) of NPR2 rs208158047 SNP in 3 cattle breeds. The experimental results showed that in Charolais, Limousin, and Blonde d'Aquitaine cattle, gene frequency of allele $\mathrm{T}$ in three cattle breeds was $0.93,0.93,0.86$ and the frequency of allele $\mathrm{C}$ was $0.07,0.07,0.12$, respectively. The frequency of $\mathrm{C}$ allele is rather lower compared to allele $\mathrm{T}$ and no genotype $\mathrm{CC}$ was observed in the investigated cattle population (Table 1). The $\mathrm{C}$ allele frequency was found higher in Blonde d'Aquitaine breed compared to Charolais and Limousin (Table 1).

Table 1. Genotype, allele frequencies and genetic diversity parameters of genotyped polymorphisms within bovine NPR2 gene

\begin{tabular}{|c|c|c|c|c|c|c|c|c|c|}
\hline \multirow[t]{2}{*}{ Locus } & \multirow[t]{2}{*}{ Breeds } & \multicolumn{2}{|c|}{$\begin{array}{l}\text { Genotype } \\
\text { frequencies } \\
(\%)\end{array}$} & \multicolumn{2}{|c|}{$\begin{array}{c}\text { Allele } \\
\text { frequencies } \\
(\%)\end{array}$} & \multicolumn{3}{|c|}{ Diversity parameter } & \multirow{2}{*}{$\begin{array}{c}\chi^{2} \\
(\alpha=0.05, \\
\mathrm{df}=1)\end{array}$} \\
\hline & & $\mathrm{TT}$ & $\mathrm{CT}$ & $\mathrm{T}$ & $\mathrm{C}$ & $\mathrm{He}$ & $\mathrm{Ne}$ & PIC & \\
\hline \multirow{4}{*}{$\begin{array}{l}\text { NPR2 } \\
r s 208158047\end{array}$} & Charolais & 0.87 & 0.13 & 0.93 & 0.07 & 0.130 & 1.15 & 0.921 & 1.19 \\
\hline & Limousin & 0.86 & 0.14 & 0.93 & 0.07 & 0.130 & 1.15 & 0.921 & 1.18 \\
\hline & Blonde d'Aquitaine & 0.76 & 0.24 & 0.88 & 0.12 & 0.211 & 1.268 & 0.853 & 1.25 \\
\hline & General & 0.85 & 0.15 & 0.92 & 0.08 & 0.147 & 1.173 & 0.908 & 1.21 \\
\hline
\end{tabular}

$\chi^{2}(0.05 ; 1)=3.84 ; \mathrm{He}$ : gene heterozygosity; Ne: effective allele numbers; PIC: polymorphism information content; $\mathrm{He}=1-\mathrm{p}(\mathrm{T})^{2}-\mathrm{p}(\mathrm{C})^{2} ; \mathrm{Ne}=1 /(1-\mathrm{He}) ; \mathrm{PIC}=\mathrm{p}(\mathrm{T})-2 \mathrm{p}(\mathrm{T})^{2} \mathrm{p}(\mathrm{C})^{2}$.

The diversity parameter of $\mathrm{He}$ is $0.13,0.13$, and 0.211 in Charolais, Limousin and Blonde d'Aquitaine cattle breeds, respectively (Table 1), which means that at a polymorphic locus, a random individual has the possibility of having any two different alleles. That is, the possibility of being heterozygote is $13 \%$ in Charolais and Limousin, and $21 \%$ in Blonde d'Aquitaine. Polymorphism information content (PIC) indicates the possibility of a marker allele derived from the same allele of its father (or mother). According to the PIC value of the three breeds' mutation site, we found that the genetic diversity of the three cattle breeds was high (PIC value $<0.25$, low genetic diversity; $0.25<$ PIC value $<0.50$, intermediate genetic diversity; and PIC value $>0.50$, high genetic diversity) (Nei and Roychoudhury, 1974). Chi-square distribution critical table, the p-value in all cattle breeds is $>0.05$, so there is no significant difference between the observed value and the expected value, and they are all in Hardy-Weinberg equilibrium (Table 1).

The results of association analysis between single nucleotide polymorphisms at intron 2 of NPR2 rs208158047 SNP and growth and carcass traits of beef cattle are shown in Table 2. For the analytical data, we found the NPR2 rs208158047 locus had a significant effect on adwg (Table 2). The TC genotype cattle's adwg between different time points except d60-120 was significantly higher than the TT genotype cattle $(\mathrm{P}<0.05)$. 
Table 2. Association analysis of mutations in NPR2 rs208158047 mutation with growth and carcass traits in three breeds cattle population

\begin{tabular}{|c|c|c|c|c|c|c|}
\hline \multirow{2}{*}{ Genotype } & \multicolumn{2}{|c|}{$\begin{array}{c}\text { rs208158047 genotypes } \\
\text { mean } \pm \text { S.E. }\end{array}$} & \multirow{2}{*}{ P-value } & \multicolumn{2}{|c|}{ Fixed effect } & \multirow{2}{*}{${ }^{+} \mathrm{R}^{2}$} \\
\hline & TT & $\mathrm{TC}$ & & Breed & Initial weight & \\
\hline \multicolumn{7}{|c|}{ Live weight trait } \\
\hline $\mathrm{d} 60(\mathrm{~kg})$ & $434.1 \pm 5.6$ & $441.6 \pm 12.3$ & 0.58 & ns & & 0.08 \\
\hline $\mathrm{d} 120(\mathrm{~kg})$ & $538.5 \pm 5.5$ & $545.7 \pm 11.9$ & 0.57 & ns & & 0.007 \\
\hline \multicolumn{7}{|c|}{ Growth related trait (adwg) } \\
\hline $\mathrm{d} 0-60(\mathrm{~kg})$ & $2.09 \pm 0.05$ & $2.39 \pm 0.11$ & 0.032 & ns & ns & 0.08 \\
\hline $\mathrm{d} 0-120(\mathrm{~kg})$ & $1.91 \pm 0.03$ & $2.06 \pm 0.06$ & 0.042 & ns & $*$ & 0.12 \\
\hline $\mathrm{d} 60-120(\mathrm{~kg})$ & $1.73 \pm 0.03$ & $1.73 \pm 0.07$ & 0.97 & ns & ns & 0.06 \\
\hline d0-sw (kg) & $1.31 \pm 0.01$ & $1.40 \pm 0.04$ & 0.046 & ns & $\mathrm{ns}$ & 0.06 \\
\hline \multicolumn{7}{|c|}{ Carcass trait } \\
\hline hcw $(\mathrm{kg})$ & $404.6 \pm 3.07$ & $406.2 \pm 4.37$ & 0.71 & ns & $* * *$ & 0.59 \\
\hline ccw $(\mathrm{kg})$ & $399.2 \pm 4.29$ & $397.5 \pm 1.95$ & 0.72 & ns & $* * *$ & 0.59 \\
\hline $\mathrm{dp}(\%)$ & $60.5 \pm 0.22$ & $60.7 \pm 0.5$ & 0.79 & $\mathrm{~ns}$ & $* *$ & 0.10 \\
\hline
\end{tabular}

d0: Fattening initial weight, d60: Body weight on 60th day, d120: Body weight on 120th day, sw: slaughter weight, hcw: hot carcass weight, ccw: cold carcass weight, dp: dressing percentage, ns: not significant; ${ }^{+} \mathrm{R}^{2}$ values derived from the General Linear Model; S.E.: standard error. ***: $\mathrm{P} \leq 0.001 ; * *: \mathrm{P} \leq 0.01 ; *: \mathrm{P} \leq 0.05$.

\section{Discussion}

Selection pressures cause specific changes on genomic regions that affect traits of economic interest together with traits involved in adaptation to climatic and stress conditions, immune response, and disease resistance (Keller and Taylor, 2008). These genomic footprints left by selection are known as selection signatures and can be used to identify loci subjected to selection (de Simoni Gouveia et al., 2014). Plenty of selection signatures have been identified in livestock species including cattle (de Simoni Gouveia et al., 2014; Xu et al., 2015), however, an important issue for many identified signatures of selection is which traits may steer selection at those loci (Kijas et al., 2012; Khan et al., 2020; Liu et al., 2020). Therefore, beside identifying loci and genes under selection pressure, investigating how they are biologically relevant is essential for understanding how the selection signatures contributed to the current phenotype (Almeida et al., 2019). The study of selection signature analysis in cattle showed that a SNP in or nearby the NPR2 gene was identified from positive selection region (Randhawa et al., 2016; Xu et al., 2015).

In the present study NPR2 rs208158047 polymorphism was found to be associated with average daily weight gain traits in different time points (Table 2). Several animal models have been implicated for C-type natriuretic peptide (CNP) and its receptor (NPR-B which is encoded by NPR2 gene) as important regulators of endochondral bone growth (Olney, 2006). After CNP binds preferentially to NPR-B, 
intracellular accumulation of cyclic GMP (cGMP) occurs and this activates several intracellular target molecules, such as cGMP-dependent protein kinases I and II (cGKI and cGKII), cyclic nucleotide regulated ion channels and cGMP-regulated phosphodiesterases which are modulating endochondral ossification (Vasques et al., 2014; Tamura et al., 2004). In mice, one disrupted $N P R 2\left(N P R 2^{+/}\right)$allele has been caused for smaller length compared to wild type (Tamura et al., 2004) and in human, NPR2 mutations were associated with short stature (Wang et al., 2015; Vasques et al., 2014) and a rare disease acromesomelic dysplasia (OMIM*602875), that is characterized by an extremely disproportional short postnatal stature.

Although NPR2 gene and its vicinity was detected in several selection signature studies comprising different breeds in both cattle and sheep (Kijas et al., 2012; Xu et al., 2015; Wei et al., 2015; Moradi et al., 2012; Ahbara et al., 2019) and possible role in growth and body size was mentioned, several research studies were conducted, investigating the association of NPR2 polymorphism on production and reproduction traits in livestock species. Function of natriuretic peptides particularly NPR2 in porcine oocyte meiotic resumption, which was associated with in vitro maturation of porcine oocytes were shown in literature (Blaha et al., 2015; Sun et al., 2017; Wang et al., 2020). On the other hand, only a genome-wide association study (GWAS) identified an association between NPR2 gene variant and growth traits in Chinese indigenous sheep breeds (Wei et al., 2015; Raza et al., 2020 b). Additionally, consistently to findings of present work QTLs were detected in the same locus where NPR2 is located on BTA8 responsible for weaning weight in Blonde d'Aquitaine cattle (Michenet et al., 2016), body weight gain in Limousin and Charolais breeds (Snelling et al., 2010), stature in multibreed cattle population (Bouwman et al., 2018) and mature body weight in Brahman cattle (Crispim et al., 2015).

\section{Conclusion}

Here we report the association of cattle selection signature NPR2 rs208158047 SNP with daily weight gain in a multibreed beef cattle population (Table 2). Selection signature validation may provide a basis for a better understanding of the forces driving artificial selection and will help to design more efficient livestock breeding programs. To the best of our knowledge, this is the first example of direct association between a widely observed selection signature near rs208158047 SNP with direct phenotype measurements - in this case, body weight gain in a multibreed beef cattle population. In conclusion, the present study revealed that NPR2 is significantly associated with weight gain, suggesting that BTA8:g.59961937-TC genotypes may serve as candidate genetic variants for the marker-assisted selection programs in terms of higher body weight gain in our and possibly other populations of beef cattle.

\section{Acknowledgements}

This study was supported by Erciyes University Scientific Research Projects Coordination Unit under grant number of FYL 2017/7097. We are grateful to Dr. Ahmed Qasim Naji for his help during laboratory experiments. Authors are also indebted to 4 Mevsim Farm Beef Operations Co. (Balıkesir, Turkey) for their support during phenotyping. 
Supplementary Table 1. Mixture and nutritional composition of young bulls' diets

\begin{tabular}{lccc}
\hline \multicolumn{1}{c|}{ Feed ingredients $(\mathrm{g})$} & Fattening starter feed $(\mathrm{g})$ & Fattening feed $(\mathrm{g})$ \\
\hline Maize silage & 3100 & 2110 \\
Dry alfalfa hay & 2130 & 800 \\
Wheat hay & 2000 & 810 \\
Sunflower meal & 2230 & 1640 \\
Wheat bran & 2000 & 3780 \\
Kernel corn & 1130 & 1520 \\
Barley & 2860 & 5980 \\
Vitamin-mineral premix ${ }^{1}$ & 35 & 35 \\
Sodium carbonate & 30 & 30 \\
Salt & 50 & 50 \\
Marble powder & 30 & 30 \\
Total & 15595 & 16785 \\
Composition & Fattening starter feed & Fattening feed \\
Roughage (\% DM) & 53.46 & 39.80 \\
Concentrate feed (\% DM) & 46.54 & 60.20 \\
Dry matter (kg) & 12.45 & 14.02 \\
Crude protein (\% DM) & 10.28 & 11.73 \\
NDF (\% DM) & 41.85 & 33.07 \\
ADF (\% DM) & 24.38 & 16.15 \\
Metabolizable energy (Mcal/kg, DM) & 2.33 & 2.60 \\
\hline
\end{tabular}

${ }^{1} \mathrm{Ca}, \mathrm{P}, \mathrm{K}$, trace elements and $\mathrm{A}, \mathrm{D}$ and $\mathrm{E}$ vitamins were supplemented to meet current need as recommended by $\mathrm{NRC}$ (2000). $\mathrm{DM}=$ dry matter; $\mathrm{NDF}=$ neutral detergent fiber; $\mathrm{ADF}=$ acid detergent fiber.

Supplementary Table 2. Summary statistics of recorded traits in Charolais, Limousin, and Blonde d'Aquitaine young

bulls

\begin{tabular}{|c|c|c|c|}
\hline \multirow[b]{2}{*}{ Phenotype } & \multicolumn{3}{|c|}{ Breeds } \\
\hline & $\begin{array}{c}\text { Charolais } \\
(\mathrm{n}=77)\end{array}$ & $\begin{array}{c}\text { Limousin } \\
(\mathrm{n}=66)\end{array}$ & $\begin{array}{c}\text { Blonde d'Aquitaine } \\
(\mathrm{n}-33)\end{array}$ \\
\hline 1 & 2 & 3 & 4 \\
\hline \multicolumn{4}{|c|}{ Live Weight Traits } \\
\hline $\mathrm{d} 0(\mathrm{~kg})$ & $296.3 \pm 48.4$ & $311.3 \pm 61.0$ & $313.5 \pm 60.3$ \\
\hline $\mathrm{d} 60(\mathrm{~kg})$ & $429.4 \pm 61.9$ & $438.2 \pm 67.9$ & $438.6 \pm 57.7$ \\
\hline $\mathrm{d} 120(\mathrm{~kg})$ & $535.6 \pm 60.7$ & $536.3 \pm 62.7$ & $547.2 \pm 61.9$ \\
\hline \multicolumn{4}{|c|}{ Growth Related Traits (adwg) } \\
\hline $\mathrm{d} 0-60(\mathrm{~kg})$ & $2.22 \pm 0.64$ & $2.11 \pm 0.33$ & $2.08 \pm 0.17$ \\
\hline $\mathrm{d} 0-120(\mathrm{~kg})$ & $1.99 \pm 0.60$ & $1.87 \pm 0.29$ & $1.94 \pm 0.20$ \\
\hline $\mathrm{d} 60-120(\mathrm{~kg})$ & $1.76 \pm 0.51$ & $1.63 \pm 0.31$ & $1.80 \pm 0.18$ \\
\hline $\mathrm{d} 0-\mathrm{sw}(\mathrm{kg})$ & $1.32 \pm 0.17$ & $1.30 \pm 0.20$ & $1.37 \pm 0.18$ \\
\hline
\end{tabular}


Supplementary Table 2 - contd.

\begin{tabular}{l|c|c|c}
\hline \multicolumn{1}{c|}{1} & 2 & 3 & 4 \\
\hline Carcass Traits & & & \\
Sw (kg) & $668.7 \pm 62.7$ & $665.4 \pm 54.7$ & $677.9 \pm 38.3$ \\
hcw (kg) & $401.1 \pm 39.5$ & $404.5 \pm 32.6$ & $412.5 \pm 27.2$ \\
ccw (kg) & $394.1 \pm 38.8$ & $397.6 \pm 32.1$ & $405.5 \pm 26.7$ \\
dp (\%) & $60.0 \pm 2.7$ & $60.8 \pm 2.5$ & $60.9 \pm 2.7$ \\
\hline
\end{tabular}

d0: Fattening initial weight, d60: Body weight on 60th day, d120: Body weight on 120th day, sw: Slaughter Weight, hcw: Hot Carcass Weight, ccw: Cold Carcass Weight, dp: Dressing percentage.

\section{References}

Ahbara A., Bahbahani H., Almathen F., Al Abri M., Agoub M.O., Abeba A., K e bed e A., Mus a H.H., M a strangelo S., Pilla F., C i a n i E., H an o t te O., Mw a cha r o J.M. (2019). Genome-wide variation, candidate regions and genes associated with fat deposition and tail morphology in Ethiopian indigenous sheep. Front. Genet., 9: 699.

A 1 m e id a O.A.C., More ira G.C.M., Re zende F.M., B o s chiero C., D e Olive ira Peixoto J., I b e 11 i A.M.G., L e du r M.C., d e Nova is F.J., C o u t in ho L.L. (2019). Identification of selection signatures involved in performance traits in a paternal broiler line. BMC Genomics, 20: 449 .

A n a nd-Srivastava M.B. (2005). Natriuretic peptide receptor-C signaling and regulation. Peptides, 26: 1044-1059.

A n d e r s s o n L. (2012). How selective sweeps in domestic animals provide new insight into biological mechanisms. J. Intern. Med., 271: 1-14.

B artels C.F., Bükülmez H., Padayatti P., Rhee D.K., van Ravenswaaij-Arts C., Pauli R.M., Mundlos S., Chit ay at D., Shih L.Y., A l-Gazali L.I., Kant S., Cole T., Morton J., Cormier-Daire V., Faivre L., Lees M., Kirk J., Mortier G.R., Le roy J., Zabel B., Kim C.A., Crow Y., Braverman N.E., van den Akker F., Warman M.L. (2004). Mutations in the transmembrane natriuretic peptide receptor NPR-B impair skeletal growth and cause acromesomelic dysplasia, type Maroteaux. Am. J. Hum. Genet., 75: 27-34.

B laha M., Nemcova L., Prochazka R. (2015). Cyclic guanosine monophosphate does not inhibit gonadotropin-induced activation of mitogen-activated protein kinase $3 / 1$ in pig cumulusoocyte complexes. Reprod. Biol. Endocrinol., 13: 1.

B ouw man A.C., Daetwyler H.D., Chamberlain A.J., Ponce C.H., Sargolzaei M., S ch en ke l F.S.,S a h a n a G.,G ovi g n on - Gi o n A.,B o i t a r d S.,D o l e z a l M.,P a u s c h H., Brøndum R.F., B ow man P.J., Thomsen B., Guldbrandtsen B., Lund M.S., S ervin B., Garrick D.J., Reecy J., Vilkki J., Bagnato A., Wang M., Hoff J.L., Sch n abel R.D., Tay lor J.F., Vinkhuy z en A.A.E., P a n itz F., B e nd ix e n C., Holm L.E., Gredler B., Hozé C., B ouss aha M., Sanchez M.P., Rocha D., Capitan A., Tribout T., Barbat A., Croiseau P., Drögemüller C., Jagannathan V., Vander Jagt C., Crowley J.J., Bieber A., Purfield D.C., Berry D.P., Emmerling R., Götz K.U., Frischknecht M., Russ I., Sölkner J., Van Tassell C.P., Fries R., S t o thard P., Ve erka m p R.F., B o i c hard D., Go d d a rd M.E., H a y e s B.J. (2018). Metaanalysis of genome-wide association studies for cattle stature identifies common genes that regulate body size in mammals. Nat. Genet., 50: 362-367.

Crispim A.C., Kelly M.J., Guimarães S.E.F., E Silva F.F., Fortes M.R.S., Wence s l a u R.R., M o or e S. (2015). Multi-trait GWAS and new candidate genes annotation for growth curve parameters in Brahman cattle. PloS ONE, 10: e0139906. 
de Simoni Gouveia J.J., da Silva M.V.G.B., Paiva S.R., de Oliveira S.M.P. (2014). Identification of selection signatures in livestock species. Genet. Mol. Biol., 37: 330-42.

FAO (2019). World Food and Agriculture - Statistical pocketbook. Rome.

K e 11 e r S.R., T a y 1 o r D.R. (2008). History, chance and adaptation during biological invasion: Separating stochastic phenotypic evolution from response to selection. Ecol. Lett., 11: 852-866.

K han R., R a za S.H.A., Gu o H., Xi a y u W., S e n W., S u ha il S.M., R a h m a n A., U 11 ah I., Abd E1-Aziz A.H., Manzari Z., Alshawi A. (2020). Genetic variants in the TORC2 gene promoter and their association with body measurement and carcass quality traits in Qinchuan cattle. PloS ONE, 15: e0227254.

Ki j a s J.W., L e n stra J.A., H a y e s B., B o it ard S., Porto Ne to L.R., S a n Cristobal M., Servin B., McCulloch R., Whan V., Gietzen K., Paiva S., Barendse W., Cian i E., R a ads ma H., Mc Ew an J., D a 1 ry mple B., International Sheep Genomics Consortium Members (2012). Genome-wide analysis of the world's sheep breeds reveals high levels of historic mixture and strong recent selection. PloS Biol., 10: e1001258.

Li u G.Y., R a za S.H.A., Z ho u L., A b d E 1 - A z i z A.H., S ab e k A., S hoore i H., A m j a d i M., $\mathrm{G}$ u i L.S. (2020). The genetic polymorphisms of melanocortin-4 receptor gene are associated with carcass quality traits in a Chinese indigenous beef cattle breed. Res. Vet. Sci., 132: 202-206.

Michenet A., B arb at M., S a intilan R., Ven ot E., Ph oc as F. (2016). Detection of quantitative trait loci for maternal traits using high-density genotypes of Blonde d'Aquitaine beef cattle. BMC Genet., 17: 88.

Moradi M.H., Nejati - Javaremi A., Moradi-Shahrbabak M., Dodds K.G., McEw a n J.C. (2012). Genomic scan of selective sweeps in thin and fat tail sheep breeds for identifying of candidate regions associated with fat deposition. BMC Genet., 13: 10.

N e i M., R o y c h o u d h u r y A.K. (1974). Sampling variances of heterozygosity and genetic distance. Genetics, 76: 379-390.

$\mathrm{Ng}$ P.C., Henik off S. (2003). SIFT: predicting amino acid changes that affect protein function. Nucleic Acids Res., 31: 3812-3814.

O 1 n e y R.C. (2006). C-type natriuretic peptide in growth: A new paradigm. Growth Horm. IGF Res., 16: S6-14.

Pitt D., Sevane N., Nicolazzi E.L., MacHugh D.E., Park S.D.E., Colli L., Martinez R., Bruford M.W., Orozco-ter Wengel P. (2019). Domestication of cattle: Two or three events? Evol. Appl., 12: 123-136.

P o t t e r L.R., A b b e y-H o s ch S., D i ck e y D.M. (2006). Natriuretic peptides, their receptors, and cyclic guanosine monophosphate-dependent signaling functions. Endocrin. Rev., 27: 47-72.

R and haw a I.A.S., Khat k a r M.S., Thom s on P.C., R a a d s m a H.W. (2016). A meta-assembly of selection signatures in cattle. PLoS ONE, 11: e0153013.

Raza S.H.A., Khan R., Abde 1 nour S.A., E 1 - Hack A., Mohamed E., Khafaga A.F., Taha A., Ohran H., Mei C., Schreurs N.M., Zan L. (2019). Advances of molecular markers and their application for body variables and carcass traits in Qinchuan cattle. Genes, 10: 717.

Raza S.H.A., Liu G.Y., Zhou L., Gui L.S., Khan R., Jinmeng Y., Chugang M., Schre ur s N.M., Ji R., Z an L. (2020 a). Detection of polymorphisms in the bovine leptin receptor gene affects fat deposition in two Chinese beef cattle breeds. Gene, 758: 144957.

Raza S.H.A., Khan S., A mjadi M., Abdelnour S.A., Ohran H., Alan azi K.M., Abd E 1 - H a ck M.E., Tah a A.E., Kh an R., Gong C., S chreurs N.M. (2020 b). Genome-wide association studies reveal novel loci associated with carcass and body measures in beef cattle. Arch. Biochem. Biophys., 694: 108543.

Raza S.H.A., Khan R., Gui L., Schreurs N.M., Wang X., Mei C., Yang X., Gong C., $\mathrm{Z}$ an L. $(2020 \mathrm{c})$. Bioinformatics analysis and genetic polymorphisms in genomic region of the bovine SH2B2 gene and their associations with molecular breeding for body size traits in Qinchuan beef cattle. Biosci. Rep., 40: BSR20192113.

Raza S.H.A., Shijun L., Khan R., Schreurs N.M., Manzari Z., Abd E1-Aziz A.H., U 11 a h I., K a s te r N., S h a h M.A., Z an L. (2020 d). Polymorphism of the PLIN1 gene and its association with body measures and ultrasound carcass traits in Qinchuan beef cattle. Genome, 63: 483-492. 
Snelling W.M., Allan M.F., Keele J.W., Kuehn L.A., McDaneld T., Smith T.P.L., S on s t e g a rd T.S., Th a $11 \mathrm{~m}$ a n R.M., B e n n e t t G.L. (2010). Genome-wide association study of growth in crossbred beef cattle. J. Anim. Sci., 88: 837-848.

S un W., L i u C., F en g Y., Z hu o G., Z hou W., F e i X., Z h ang Z. (2017). Macrophage colonystimulating factor (M-CSF) is an intermediate in the process of luteinizing hormone-induced decrease in natriuretic peptide receptor 2 (NPR2) and resumption of oocyte meiosis. J. Ovarian Res., 10: 68 .

Ta mura N., G arber s D.L. (2003). Regulation of the guanylyl cyclase-B receptor by alternative splicing. J. Biol. Chem., 278: 48880-48889.

Tamura N., Doolittle L.K., Hammer R.E., Shelton J.M., Richardson J.A., Garb e r s D.L. (2004). Critical roles of the guanylyl cyclase B receptor in endochondral ossification and development of female reproductive organs. Proc. Natl. Acad. Sci., 101: 17300-17305.

Tsuji T., Kunieda T. (2005). A loss-of-function mutation in natriuretic peptide receptor 2 (NPR2) gene is responsible for disproportionate dwarfism in $\mathrm{cn} / \mathrm{cn}$ mouse. J. Biol. Chem., 280: 14288-14292.

Vas que s G.A., Arnhold I.J.P., J org e A.A.L. (2014). Role of the natriuretic peptide system in normal growth and growth disorders. Horm. Res. Paediatr., 82: 222-229.

Wang L., R a za S.H.A., Gu i L., L i S., Li u X., Yang X., Wang S., Z a n L., Z h a o C. (2020). Associations between UASMS2 polymorphism in leptin gene and growth, carcass and meat quality traits of cattle: a meta-analysis. Anim. Biotech., doi: 10.1080/10495398.2020.1805327.

Wang S.R., Jacobsen C.M., Carmichael H., Edmund A.B., Robinson J.W., O1ney R.C., Miller T.C., Moon J.E., Mericq V., Potter L.R., Warman M.L., H i r s ch horn J.N., D a u ber A. (2015). Heterozygous mutations in natriuretic peptide receptorB (NPR2) gene as a cause of short stature. Hum. Mutat., 36: 474-481.

We i C., Wang H., Li u G., Wu M., Ca o J., Liu Z., Liu R., Zhao F., Zhang L., Lu J., $\mathrm{D} \mathrm{u} \mathrm{L.} \mathrm{(2015).} \mathrm{Genome-wide} \mathrm{analysis} \mathrm{reveals} \mathrm{population} \mathrm{structure} \mathrm{and} \mathrm{selection} \mathrm{in} \mathrm{Chinese} \mathrm{indig-}$ enous sheep breeds. BMC Genomics, 16: 194.

Xu L., Bickhart D.M., Cole J.B., Schroeder S.G., Song J., Van Tassell C.P., Sons te g a r d T.S., L i u G.E. (2015). Genomic signatures reveal new evidences for selection of important traits in domestic cattle. Mol. Biol. Evol., 32: 711-725.

Received: 13 XI 2020

Accepted: 15 IV 2021 